\title{
A statistical study of the monsoon trough and associated tropical cyclogenesis over the western North Pacific
}

\author{
Tao Feng ${ }^{1,2,3, *}$ and Tao Zheng ${ }^{3}$ \\ ${ }^{I}$ Key Laboratory of Marine Hazards Forecasting, Ministry of Natural Resources, Hohai University, Nanjing, China \\ ${ }^{2}$ Southern Marine Science and Engineering Guangdong Laboratory (Zhuhai), Zhuhai, China \\ ${ }^{3}$ College of Oceanography, Hohai University, Nanjing, China
}

\section{Article history:}

Received 30 August 2021

Revised 5 November 2021

Accepted 15 December 2021

Keywords:

Tropical cyclogenesis, Monsoon trough, Daily genesis rate

\section{Citation:}

Feng, T. and T. Zheng, 2021: A statistical study of the monsoon trough and associated tropical cyclogenesis over the western North Pacific. Terr. Atmos. Ocean. Sci., 32, 1215-1226, doi: 10.3319/TAO.2021.12.15.02

\begin{abstract}
Previous studies have suggested that a strong monsoon trough is favorable for tropical cyclogenesis over the western North Pacific. This study reexamined the relationship between the monsoon trough and tropical cyclogenesis using a recently developed daily monsoon trough index that captures the seasonal generation of tropical cyclones (TCs). The connection between the value of the index and the morphology of the monsoon trough is established for further categorization and composition. During 1979 - 2020, a total of $734(57.3 \%)$ TC formations were associated with an active monsoon trough, while $42.7 \%$ TCs formed when the monsoon trough was categorized as inactive. With a climatological genesis rate of $8.4 \%$, the daily genesis rate ranged from 13.9 to $24.6 \%$ with an active monsoon trough, which was significantly higher than that without an active monsoon trough. The genesis rate gradually increased with the intensification of a monsoon trough with a peak of $24.6 \%$ when an extraordinarily strong monsoon trough existed, with approximately one TC formation every four days. The intensity of the monsoon trough affected the favored TC genesis latitude and longitude, and a stronger monsoon trough favored northeastward generation, exhibiting different track types due to different steering flows.
\end{abstract}

\section{INTRODUCTION}

The lower-tropospheric monsoon trough is a vital planetary-scale system responsible for most tropical cyclone (TC) formations over the western North Pacific. Previous studies have suggested that over $70 \%$ of TCs form in the vicinity of the monsoon trough due to favorable environmental conditions, such as large-scale cyclonic shear, small vertical wind shear, high mid-tropospheric relative humidity, and active moist convection (Gray 1968; Wu et al. 2012, 2020b; Ha et al. 2013; Feng et al. 2014; Huangfu et al. 2017, 2018; Tan et al. 2019).

Among the hundreds of studies focusing on the northwestern Pacific monsoon trough, the definition of the monsoon trough and related TCs differs significantly, confusing the understanding of these results. The first discrepancy is the timescale of the monsoon trough. Lander $(1994,1996)$ and Holland (1995) defined a monsoon trough as a zonally elongated sheared region with southwesterlies in the

\footnotetext{
* Corresponding author

E-mail:fengtao@hhu.edu.cn
}

south and easterlies in the north from daily synoptic maps. Harr and $\mathrm{Wu}$ (2011) stated that the monsoon trough evolves on different timescales from daily to monthly, but they still defined a monsoon trough on a daily basis. However, Molinari and Vollaro (2013) proposed several critical drawbacks to defining the monsoon trough on a daily basis, e.g., noncontiguous vorticity regions, too much influence from TCs and the Madden-Julian Oscillation (MJO). They argued that the monsoon trough should be described as positive relative vorticity averaged over at least several months to eliminate these higher frequency signals. However, the identification of the monsoon trough from daily synoptic maps is either a practical requirement for weather forecasting or a scientific need where many scientific problems can be easily explained from the daily evolution of the monsoon trough (e.g., Ritchie and Holland 1999; Gao and Li 2011; Cao et al. 2014a, b; Wu et al. 2020a). To overcome the drawbacks mentioned above, Feng et al. (2020a) proposed a daily definition and proposed a monitoring index that better represents the monsoon trough on different timescales. 
They defined the monsoon trough as an elongated area on a weather map showing relatively low atmospheric pressure consisting of easterly trade winds and westerly monsoonal winds. This definition emphasizes the role of the westerly monsoonal wind involving the monsoon trough, which separates the monsoon trough from the equatorial trough induced by trade northeasterlies during boreal winter. They found that the new definition better illustrates the seasonal and interannual variations in the monsoon trough.

The second issue is how to define whether a TC is formed in a monsoon trough. Strictly, when a TC is embedded in the vicinity of the monsoon trough at the time of genesis, this event is associated with the monsoon trough. When defining the monsoon trough on a synoptic map, it is convenient to analyze whether a TC is formed in a monsoon trough (Briegel and Frank 1997; Ritchie and Holland 1999; Feng et al. 2014; Zong and Wu 2015). Through this approach, the monsoon trough accounts for approximately $70 \%$ of the total genesis events during boreal summer. The deficiency of this approach is its reproducibility, as this approach requires author judgment on the synoptic circulation pattern. Based on Ritchie and Holland's (1999) categories, Yoshida and Ishikawa (2013) developed a series of algorithms and criteria that can objectively identify favored circulation patterns leading to tropical cyclogenesis. They reported that $64 \%$ of the TCs were related to the monsoon trough throughout the entire year. However, these algorithms require TC genesis information. These algorithms cannot be used to identify the circulation pattern without TC formation. Consequently, they are unable to calculate the daily genesis rate to investigate the genesis capacity of the monsoon. Another approach is to define the monsoon trough as the elongated region with positive relative vorticity averaged for at least several months, e.g., from June to October. The region represents a climatological or large-scale background with a monsoon trough. Then, TCs with genesis locations inside the positive vorticity region are counted as forming in the monsoon trough (Wu et al. 2012; Molinari and Vollaro 2013). However, as the monsoon trough evolves daily, the daily position of the monsoon trough is not necessarily in the climatological region, which may lead to an overestimation or underestimation of the TC genesis frequency. Molinari and Vollaro (2013) proposed that $73 \%$ of TCs form within the monsoon trough. However, they also proposed that $100 \%$ TC formation occurs from January to March, which is unreasonable because the monsoon trough is commonly established following the outburst of the western North Pacific summer monsoon (Wang and LinHo 2002; Wu 2002).

Due to the abovementioned discrepancy, it remains a problem to give a complete statistical relationship between the monsoon trough and tropical cyclogenesis. The basic questions are as follows: (1) How frequently are TCs formed inside a monsoon trough? (2) What is the possibility that a monsoon trough fosters a TC? A newly developed daily monsoon trough index (Feng et al. 2020a), which is demonstrated to well-represent the daily variation in the monsoon trough throughout the entire year, provides a proxy to answer these questions. The present study intends to reveal the statistical relationship between the monsoon trough and tropical cyclogenesis using this daily index. The rest of this paper is organized as follows: section 2 describes the dataset and methodology. In section 3, the connection between the monsoon trough and TC genesis is revealed. In section 4, the genesis capacity in association with the intensity of the monsoon trough is investigated. Finally, in section 5, the conclusions and discussion are presented.

\section{DATA AND METHODOLOGY}

\subsection{Datasets}

The daily atmospheric fields have a horizontal resolution of $2.5^{\circ} \times 2.5^{\circ}$ and 17 vertical pressure levels spanning the period from 1979 to 2020, which were adopted from the National Centers for Environmental Prediction Department of Energy (NCEP-DOE) AMIP-II Reanalysis (NCEP/ NWS/NOAA/DOC 2000; Kanamitsu et al. 2002). The sixhourly TC best track data are adopted from the International Best Track Archive for Climate Stewardship (IBTrACS) version 4 (Knapp et al. 2010, 2018). The genesis time is defined as the first occurrence of the maximum near-surface wind speed reaching $35 \mathrm{kt}$.

\subsection{Definition of the Monsoon Trough Index}

This study employs a revised monsoon trough index (MTI) developed by Feng et al. (2020a), which is suitable for monitoring the daily variation in the monsoon trough. The definition of the monsoon trough is an elongated area on a weather map showing relatively low atmospheric pressure consisting of easterly trade winds and westerly monsoonal winds. The calculation of the MTI is separated into three steps, following the above definition (Fig. 1):

(1) Step 1: Extract the monsoon trough signal by applying

the TC removal algorithm.

The monsoon trough is a favorable region for tropical cyclogenesis. When the TC forms, TC circulation exerts a significant impact on planetary-scale ambient wind fields (Hsu et al. 2008). Sometimes, trough-like circulation cannot be directly identified from the synoptic-scale map since TC circulation usually interacts with the general circulation (e.g. Hsu et al.2008) or an event breakdowns the monsoon trough (Ferreira and Schubert 1997; Cao et al. 2013). As a result, the TC circulation should be removed before calculating the monsoon trough index to avoid inclusion of the TC signal. First, the TC removal approach developed by Kurihara et al. $(1993,1995)$ is applied, which objectively extracts the ambient circulation by removing an asymmetric TC. 


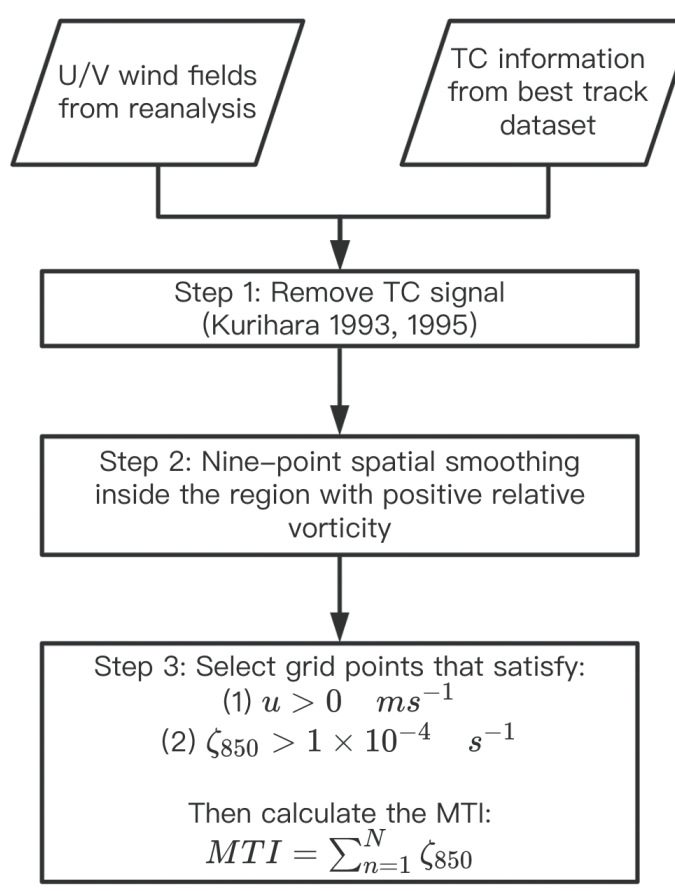

Fig. 1. Flow chart for calculating the monsoon trough index.

(2) Step 2: Nine-point spatial smoothing is performed inside the monsoon trough region (positive relative vorticity) to eliminate high-frequency noise. Following these steps, a smoothing monsoon trough signal can be easily identified from the synoptic map. The results of this preprocessing are shown in Fig. 2 of Feng et al. (2020a).

(3) Step 3: Calculate the daily index following

$$
M T I=\alpha \sum_{n=1}^{N} \zeta_{850}
$$

In Eq. (1), $\zeta_{850}$ is the relative vorticity at $850 \mathrm{hPa}$, and $N$ is the grid point that satisfies the following two criteria: (1) eastward wind exists $\left(u>0 \mathrm{~m} \mathrm{~s}^{-1}\right)$ at $850 \mathrm{hPa}$ and (2) the relative vorticity exceeds a threshold $\left(\zeta_{850}>1 \times 10^{-6} \mathrm{~s}^{-1}\right)$ within the tropical western North Pacific $\left(5^{\circ}-25^{\circ} \mathrm{N}, 120^{\circ} \mathrm{E}\right.$ $-180^{\circ}$ ). The constant $\alpha$ is a nondimensional scaling coefficient that is $10^{-6}$ in this study.

Previous studies have usually defined the monsoon trough index by using the average of the positive relative vorticity at $850 \mathrm{hPa}$ in the region $5^{\circ}-25^{\circ} \mathrm{N}, 120^{\circ} \mathrm{E}-180^{\circ}$ (hereafter the RVI) (e.g., Wu et al. 2012; Huangfu et al. 2017; Li et al. 2017). The critical advance of the current MTI definition is the first criterion in which westerlies are introduced as a necessary condition. Lower tropospheric westerlies are a vital component of the East Asian monsoon trough. The criterion separates the monsoon trough from the equatorial trough induced by trade easterlies. Feng et al. (2020a) demonstrated that the new MTI was better at representing the seasonal migration of the monsoon trough than the RVI, which did not consider the role of monsoonal westerlies.

\section{STATISTICAL RELATIONSHIP BETWEEN THE MONSOON TROUGH AND TCS}

As the monsoon trough is the most favorable region for tropical cyclogenesis over the western North Pacific, the seasonal variation in TC occurrence usually follows the evolution of the monsoon trough. Figure 2 shows the seasonal variation in TC occurrence, MTI, and RVI averaged from 1979 to 2020. Generally, the northwestern Pacific typhoon season lasts from June until November, which accounts for $83.3 \%$ of the total TC formations. The average genesis number is less than two in other months. During most vigorous months from July to October, more than four TCs form each month due to favorable environmental conditions. The two monsoon trough indices generally follow the seasonal variation in TCs. The discrepancy between the two indices appears from November to January; the RVI illustrates a peak neither consistent with the seasonal cycle of the monsoon trough nor correlated with TC occurrence, while the MTI better captures the character of TC occurrence. A sharp decrease in TC number can be found in November due to the westward retreat of the western North Pacific summer monsoon (Wang and LinHo 2002; Wu 2002), but the value of the RVI in November has an amplitude similar to those in August and September. The misrepresentation of the RVI is because the trade easterlies can also induce remarkable positive relative vorticity along the equator, which is not associated with the western Pacific summer monsoon. 


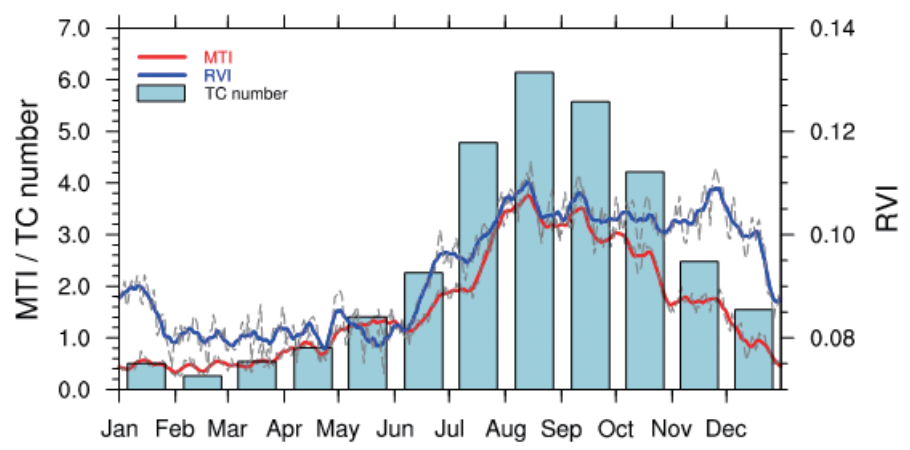

Fig. 2. Monthly average TC genesis number (bar), the MTI (red curve), and the relative vorticity index, RVI (blue curve). The MTI and RVI data were smoothed using a 9-day running average with gray dashed curves showing the raw data.

Figure 3 shows the composited horizontal winds at $850 \mathrm{hPa}$ of the monsoon trough with different intensities and associated tropical cyclogenesis. As the definition of the monsoon trough requires low-level westerlies, the shaded regions with positive relative vorticity (Figs. 3a - b) are not recognized as a monsoon trough because of the overlapping easterly wind. The small value of the MTI denied the existence of a monsoon trough in these cases. Such a definition is an essential difference from Molinari and Vollaro (2013), who considered the equatorial trough induced by trade easterly wind to be a monsoon trough. They also counted TC genesis events within this equatorial trough as cases that formed in the monsoon trough. In this study, the cases with an MTI $=0.0$ and $0.0<\mathrm{MTI}<2.0$ are categorized as NoMT and inactive, respectively (Table 1). The cases with MTI $\geq$ 2.0 are classified as active and are categorized as Cat. 1 4 for further discussion (Table 1). Those TC formations in Cat. 1 - 4 days are considered to be associated with an active monsoon trough.

The average genesis locations for these two categories are $9.5^{\circ} \mathrm{N}, 144.3^{\circ} \mathrm{E}$ and $12.8^{\circ} \mathrm{N}, 139.5^{\circ} \mathrm{E}$ (Table 1), which are located in the lower latitudes and the western part of the western North Pacific, respectively (Figs. 3a - b). Since the MTI is greater than 2.0, the composite maps depict a well-established monsoon trough extending from the South China Sea to the central North Pacific, as shown in Figs. $3 \mathrm{c}-\mathrm{f}$. The region with positive vorticity can be separated into two sections from the pattern of horizontal winds: a sheared region west of $150^{\circ} \mathrm{E}$ featuring significant meridional shear with westerlies in the south and easterlies in the north and a convergent region to the east of $150^{\circ} \mathrm{E}$ featuring westerlies in the west and easterlies in the east. This structure is consistent with the morphology classification that divides the monsoon trough into a monsoon shearline and a confluence region regardless of the strength of the monsoon trough (Holland 1995; Ritchie and Holland 1999; Feng et al. 2014; Zhao et al. 2015). These cases with a MTI above 2.0 are categorized as active following Feng et al. (2020a). The prominent difference for cases with a greater MTI is the stronger cross-equatorial monsoonal southwesterlies to the south of the monsoon trough. With the intensification of the monsoon trough, the average genesis location gradually shifts northeastward from $13.3^{\circ} \mathrm{N}, 140.9^{\circ} \mathrm{E}$ to $15.3^{\circ} \mathrm{N}$, $142.0^{\circ} \mathrm{E}$ (Table 1), illustrating the impact of the monsoon trough intensity on the average genesis location.

As discussed in the introduction, there are several definitions to determine whether a TC is formed in the monsoon trough. In the present study, TC formation events with MTIs above 2.0 are all counted as monsoon trough formation events, although a small number of cases occur outside the region of the monsoon trough due to daily migration. For instance, Fig. 3c is a composite of all daily average circulations with MTIs between 2.0 and 4.0, and TC formation events on these days are all categorized in association with the monsoon trough. Such a definition may overestimate the influence of the monsoon trough on tropical cyclogenesis because the TCs that formed outside the region of the monsoon trough were counted. A pattern recognition approach, such as that proposed by Yoshida and Ishikawa (2013), may be a possible approach to address this problem.

Figure 4 shows the spatial distribution of TC occurrence binned for every $2.5^{\circ} \times 2.5^{\circ}$ rectangle for different intensities of the monsoon trough. For NoMT category cases, TC formations usually occur over the ocean south of $10^{\circ} \mathrm{N}$ (Fig. $4 \mathrm{a}$ ). When the monsoon trough is categorized as inactive, the preferred genesis location is over the ocean around the Philippines with a slightly southeastward extension (Fig. 4b). When the monsoon trough is active with an MTI between 2.0 and 4.0, the pattern of the preferred development location (Fig. 4c) is similar to that of inactive cases (Fig. 4b). However, the TC genesis rate remarkably increases from $6.9 \%$ (448 TCs formed in 6468 days) in the inactive category to $13.9 \%$ (377 TCs formed in 2706 days) in the Cat. 1 (Table 1). The genesis capacity is investigated in detail in section 4, and this section focuses on the favorable genesis region. When the MTI is between 4.0 and 6.0, the preferred genesis region shifts eastward (Fig. 4d) with an average genesis location at $13.8^{\circ} \mathrm{N}, 142.9^{\circ} \mathrm{E}$ (Table 1). 

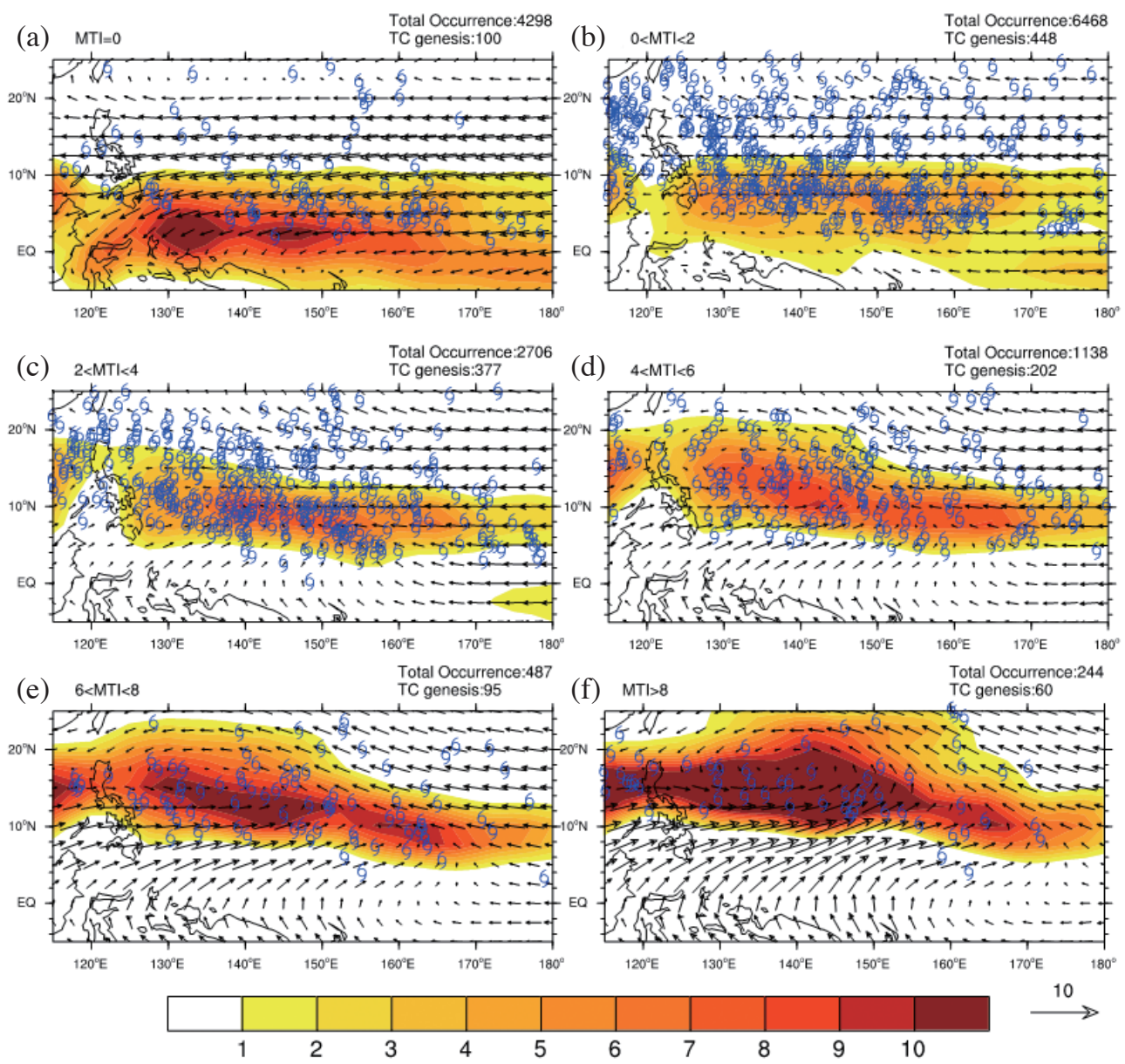

Fig. 3. Composited relative vorticity (shaded, units: $10^{-5} \mathrm{~s}^{-1}$ ) and the mean horizontal winds (vectors) at 850 hPa for cases (a) NoMT, $M T I=0$; (b) inactive, $0<M T I \leq 2$; (c) Cat. 1, $2<M T I \leq 4$; (d) Cat. 2, $4<M T I \leq 6$; (e) Cat. 3, $6<M T I \leq 8$; and (f) Cat. 4, MTI $>8$. The units for $M T I$ are s $^{-1}$. Blue TC symbols denote genesis locations.

Table 1. Statistics of the TC genesis number and average genesis location based on the monsoon trough index (MTI) from 1979 to 2020.

\begin{tabular}{cccccc}
\hline Index & Categorization & Days & TC number & Daily genesis rate & Average genesis location \\
\hline MTI $=0$ & NoMT & 4298 & 100 & 0.023 & $9.5^{\circ} \mathrm{N}, 144.3^{\circ} \mathrm{E}$ \\
$0<\mathrm{MTI} \leq 2$ & Inactive & 6468 & 448 & 0.069 & $12.8^{\circ} \mathrm{N}, 139.5^{\circ} \mathrm{E}$ \\
$2<\mathrm{MTI} \leq 4$ & Cat. 1 & 2706 & 377 & 0.139 & $13.3^{\circ} \mathrm{N}, 140.9^{\circ} \mathrm{E}$ \\
$4<\mathrm{MTI} \leq 6$ & Cat. 2 & 1138 & 202 & 0.178 & $13.8^{\circ} \mathrm{N}, 142.9^{\circ} \mathrm{E}$ \\
$6<\mathrm{MTI} \leq 8$ & Cat. 3 & 487 & 95 & 0.195 & $14.0^{\circ} \mathrm{N}, 143.7^{\circ} \mathrm{E}$ \\
MTI $>8$ & Cat. 4 & 244 & 60 & 0.246 & $15.3^{\circ} \mathrm{N}, 142.0^{\circ} \mathrm{E}$ \\
\hline
\end{tabular}



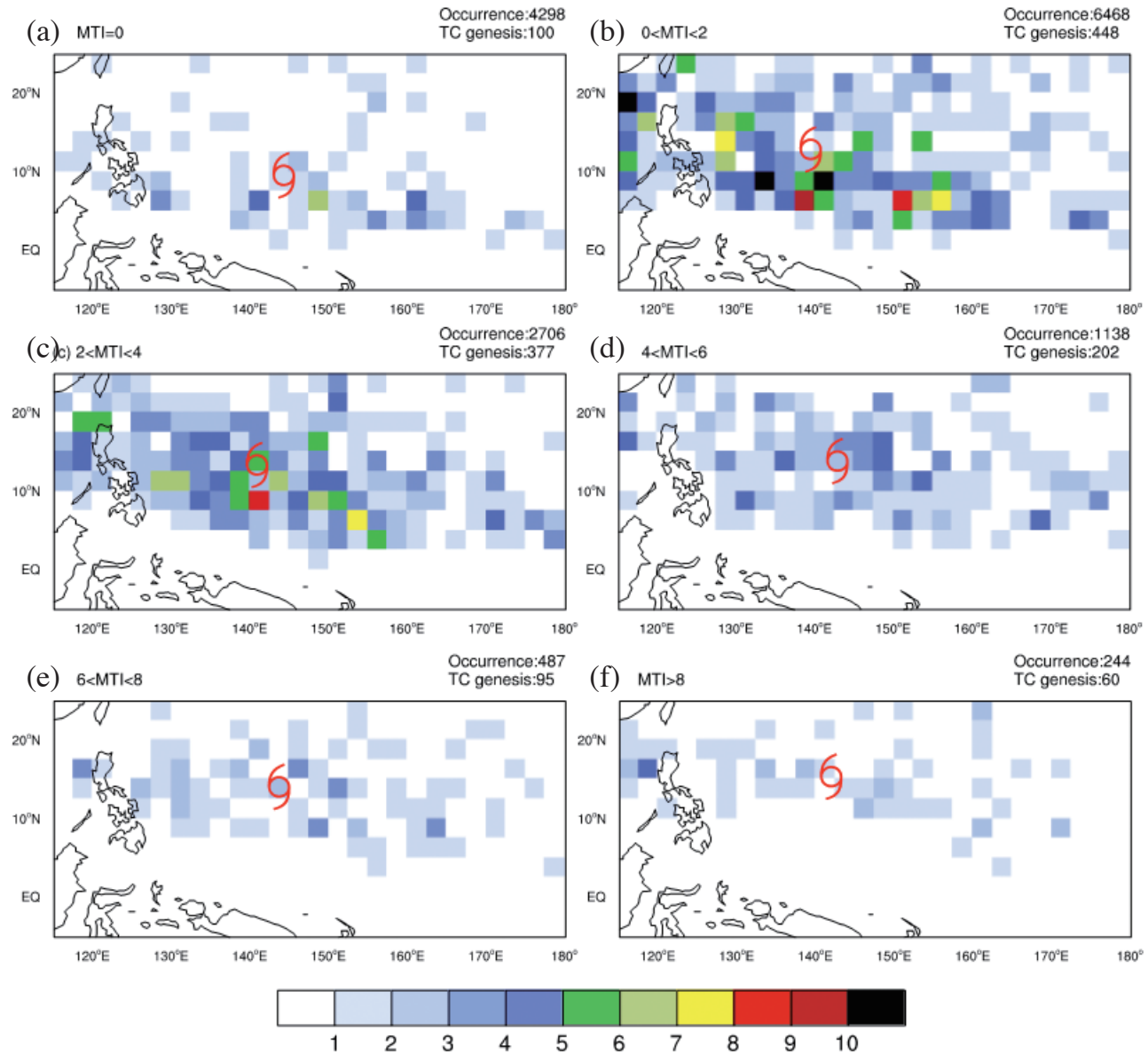

Fig. 4. Accumulated TC genesis frequency for cases (a) NoMT, $M T I=0$; (b) inactive, $0<M T I \leq 2$; (c) Cat. $1,2<M T I \leq 4$; (d) Cat. $2,4<M T I \leq 6$; (e) Cat. 3, $6<M T I \leq 8$; and (f) Cat. 4, MTI $>8$. The binned box is $2.5^{\circ} \times 2.5^{\circ}$. The TC symbol denotes the average genesis location.

When the MTI is above 6 , TCs prefer to form at relatively higher latitudes (Figs. $4 \mathrm{e}-\mathrm{f}$ ) with average latitudes of $14.0^{\circ}$ and $15.3^{\circ} \mathrm{N}$ (Table 1$)$.

The TC tracks are statistically correlated to the genesis location, which is ascribed to the different ambient steering flows (Lander 1996; Liang and Wu 2015; Zhou et al. 2018). Figure 5 shows the TC occurrence frequency after genesis, which indicates the preferred track type. For cases with an MTI equal to 0 , the TC usually moves westward across the Philippine Islands into the South China Sea. When TCs are generated in cases with MTIs between 0.0 and 2.0, they move westward to the South China Sea or recurve northward along the eastern coast of Taiwan. The track type for cases with an MTI between 2.0 and 4.0 is preferable to the northeastward recurve, and the westward track is more likely to cross the Bashi Channel rather than traverse the Philippine Islands. After the formation over the ocean for cases with an MTI above 4.0, TCs prefer to move northwestward toward Taiwan Island and the East Asian continent. However, there is no remarkable preferred track for extreme cases with an MTI greater than 8 . The plausible reason for this is that the genesis location spreads over the ocean without a dominant pattern of steering flow

Statistically, when defining the monsoon trough as active for cases with an MTI $>2.0$, there is a total of 734 $(57.3 \%) \mathrm{TCs}$, which is the sum of TC numbers from Cat. 1 to 4 in Table 1 . This percentage is less than that reported in previous studies, which suggests that nearly $70 \%$ of TC formations are associated with the monsoon trough (e.g., Ritchie and Holland 1999). The plausible reason for this is discussed in the last section.

\section{TC GENESIS CAPACITY OF THE MONSOON TROUGH}

The genesis capacity is essential to the evaluation of the possibility of TC formation in a monsoon trough environment. The daily genesis rate (DGR) is calculated by dividing the TC number by the total number of sample days in different MTI ranges. The DGR represents the capacity of large-scale circulation for generating TCs. A higher DGR indicates that TCs are more likely to form in such a circulation background. As shown in Fig. 6, the climatological DGR was 0.084 from 1979 to 2020 , i.e., one TC 

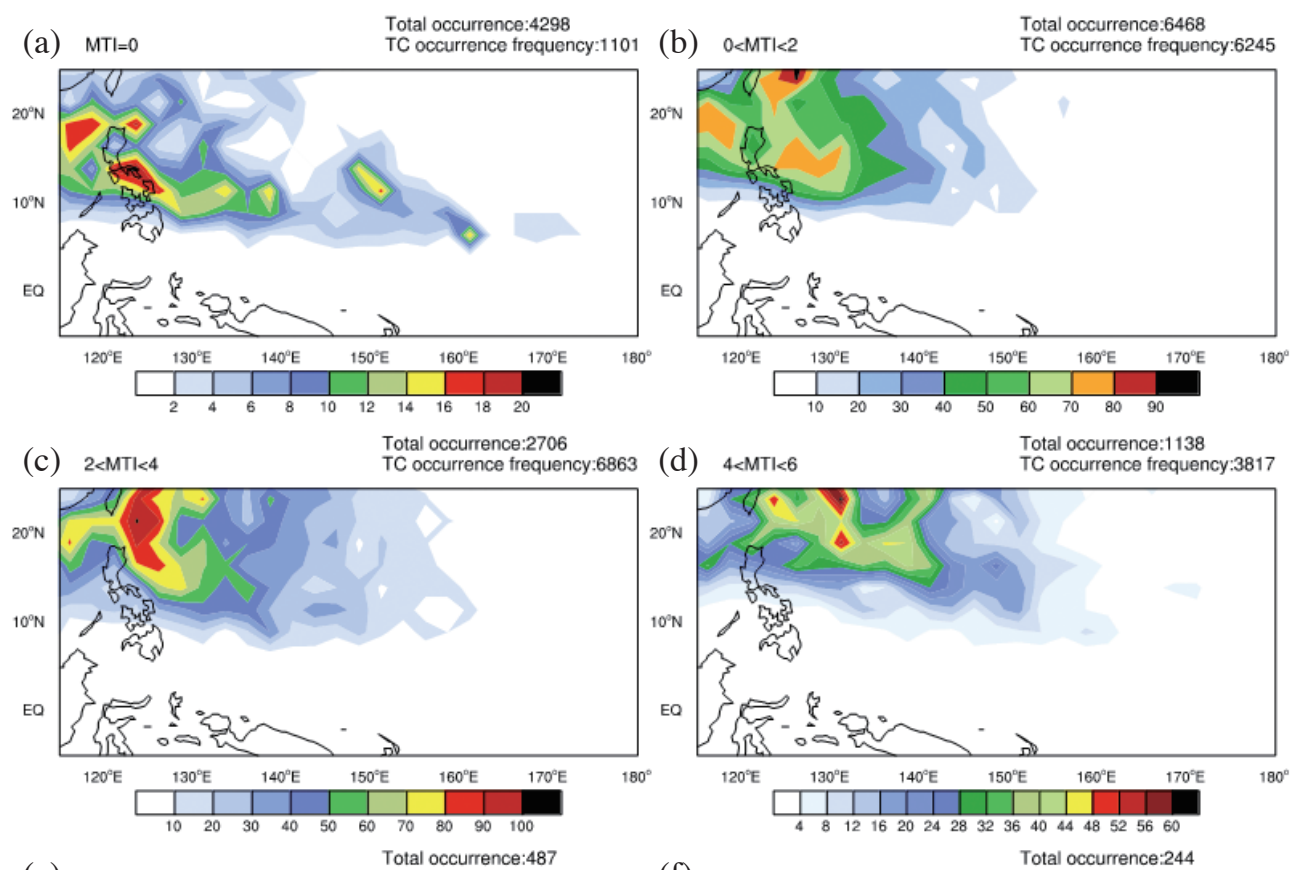

(e) $6<\mathrm{MTT}<8$

Total occurrence: 487
TC occurrence frequency:2536
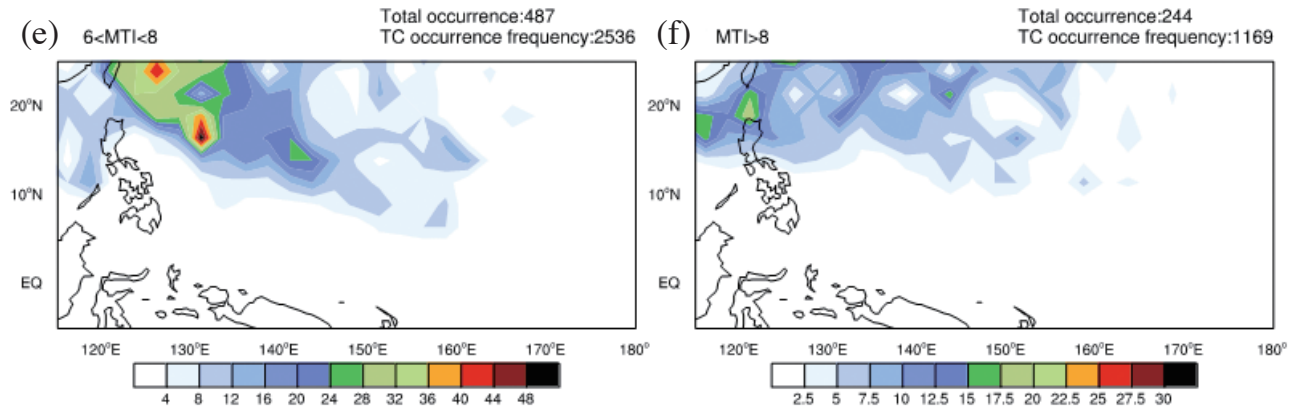

Fig. 5. Accumulated TC occurrence frequency for cases that formed in the day with (a) NoMT, MTI =0; (b) inactive, $0<M T I \leq 2$; (c) Cat. 1, $2<$ $M T I \leq 4$; (d) Cat. 2, $4<M T I \leq 6$; (e) Cat. 3, $6<M T I \leq 8$; and (f) Cat. 4, MTI>8. The binned box is $2.5^{\circ} \times 2.5^{\circ}$.

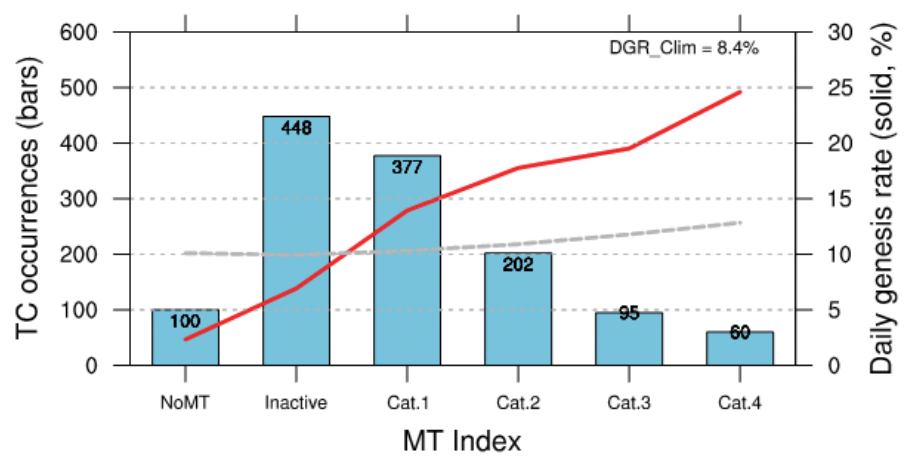

Fig. 6. The number of tropical cyclogenesis events (bar) and DGRs (solid red curve) in association with the index MTI from 1979 to 2020 . The dashed line denotes the $95 \%$ confidence level. 
formed every twelve days. For NoMT and inactive cases, the DGRs were only 0.023 and 0.069 (Table 1) without statistical significance, which were less than the climatological rate. When the monsoon trough becomes active (Cat. 2), the DGR jumps to 0.139 , exceeding $95 \%$ statistical significance. The peak DGR (0.246) appears for the Cat. 4 cases, indicating that approximately one TC forms every four days. These results suggest that a strong monsoon trough results in a higher possibility for tropical cyclogenesis. When an active monsoon trough is established, the genesis rate is between 0.139 and 0.246 , which is approximately four to eight days for TC formation. Interestingly, this frequency is consistent with the periodicity ( 3 - 8 days) of the dominant synoptic-scale waves over the western North Pacific (e.g., Takayabu and Nitta 1993), highlighting the role of the interaction between the monsoon trough and equatorial waves in TC formations.

Figure 7 shows the spatial distribution of the DGR in each grid cell over the western North Pacific. The DGR in each grid cell increases with the strengthening of the monsoon trough. Another notable feature is the inhomogeneous genesis rate in the eastern and western regions for Cat. 2 and 3 cases. The geneses are concentrated in the western part of the tropical northwestern Pacific (Fig. 7c), as the monsoon trough only extended to approximately $150^{\circ} \mathrm{E}$ in these cases (Fig. 3c). However, the genesis rate is almost homogeneously distributed in the latitude belt between $10^{\circ}$ and $20^{\circ} \mathrm{N}$ in the background with a strong monsoon trough (Figs. 7d - f). When the monsoon trough intensifies, the eastern end of the strong relative vorticity can reach nearly the dateline (Fig. 3). Thus, the regions over the tropical western North Pacific are all favorable for tropical cyclogenesis due to the large-scale cyclonic vorticity and monsoonal northeastward moisture transport in this latitude belt. After dividing the tropical western North Pacific by $145^{\circ} \mathrm{E}$ longitude, the genesis rates in the western and eastern parts are calculated individually. When the monsoon trough intensifies, the genesis rate in the western part only increases from 0.081 to $0.123 \mathrm{TC}$ per day. In contrast, the genesis rate in the eastern part increases twice from 0.058 to 0.123 TC per day (Figs. $7 \mathrm{c}-\mathrm{f})$. With the intensification of the monsoon trough, the genesis rate in the western part is less affected, while the genesis rate in the eastern part is remarkably higher. These results are consistent with previous studies showing that the TC geneses in the southeastern region are more correlated with the monsoon trough (e.g., Wu et al. 2012). (a) $M T l=0$

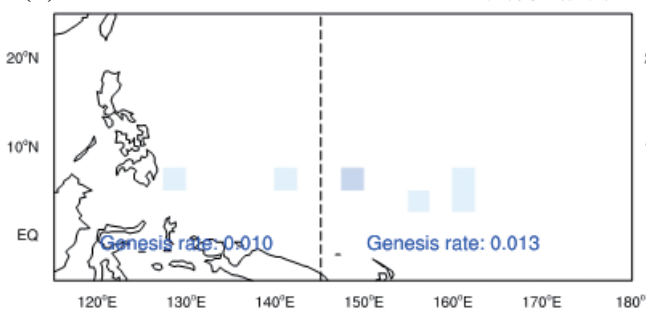

(c) $2<M T<4$

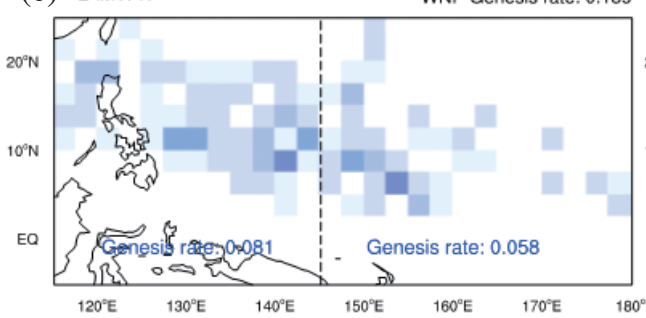

(b) $0<\mathrm{MTK}<2$

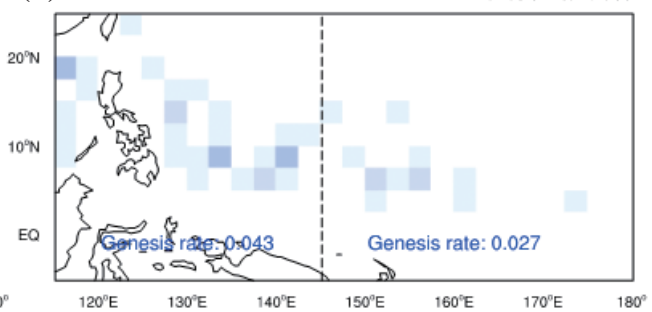

(d) $4<M T K<6$

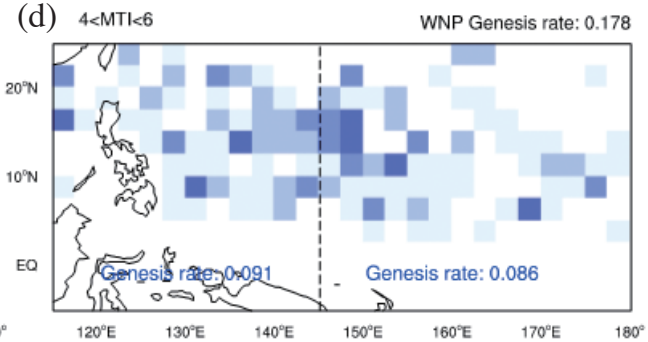

(e) $6<M T K<8$

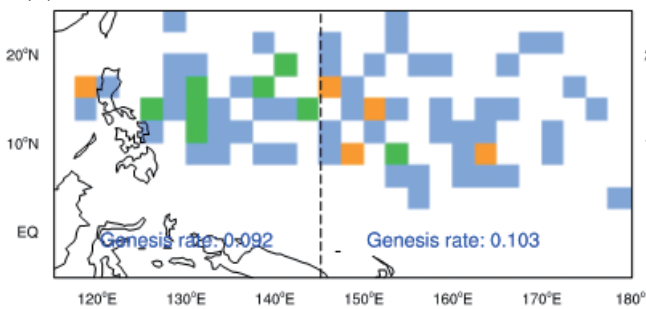

(f) $M T 1>8$ WNP Genesis rate: 0.246

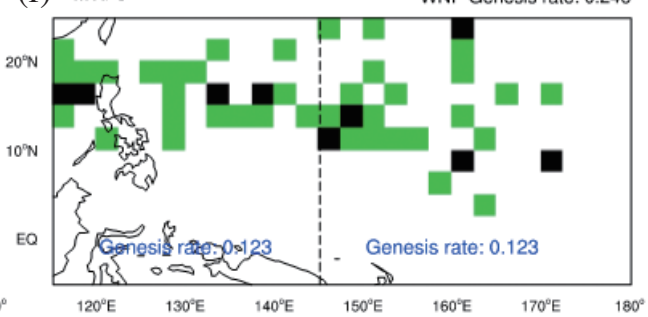

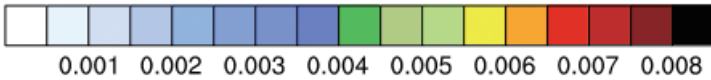

Fig. 7. Same as Fig. 4 except for daily genesis rate. 
The samples with different MTIs were not evenly distributed in each season. The seasonal variations in the monsoon trough and associated TC formations are illustrated in Fig. 8. During boreal winter, the circulation patterns are primarily classified into NoMT or inactive categories (Fig. 8a) due to the prevailing trade easterlies over the western North Pacific, accompanied by a low TC genesis rate (Figs. 8b-c). In spring, the southwesterly monsoonal winds gradually penetrated the South China Sea and the western North Pacific, favoring the establishment of the monsoon trough. In May, 23.8 days were categorized as NoMT or inactive, and 5.3 days were categorized as having a Cat. 1 monsoon trough (Fig. 8a). During summer, there was a pronounced increase in the days with an active monsoon trough (Cat. 1 - 4) in July. This increase was consistent with the seasonal evolution of the monsoon trough, in which a stable monsoon trough circulation was usually established in mid-July (Wu 2002; Feng et al. 2020a). The month with the most active monsoon trough was August, and 11.4 days were considered very active (Cat. 2 - 4), and 8.5 days were marked as Cat. 1 (Fig. 8a). Although August was the most active month for the monsoon trough, there were 11.1 days without an active monsoon trough (Fig. 8a). During these days, the monsoon trough experienced a breakdown (Ferreira and Schubert 1997; Cao et al. 2013) or northward migration (Lander 1996; Feng et al. 2014) without an active trough over the tropical western North Pacific. The TC genesis rate also experienced a seasonal cycle in which the peak genesis rate occurred during July and September (Fig. 8b). Moreover, some drastic fluctuations in the DGR were found for Cat. 3 and 4 cases during January and May (Fig. 8c), which may be ascribed to the small sample size. However, these cases with extraordinary variation in the monsoon trough outside the summer monsoon may deserve examination and explanation.

During the entire typhoon season of the western North Pacific (from May to November), the relationship between the DGR and the monsoon trough intensity is revealed in Fig. 8c. Focusing on the boreal summer, the DGR for Cat. 3 cases were greater than Cat. 2 cases by approximately 0.03 TC per day. The DGR for Cat. 2 cases was generally greater than Cat. 1 cases by approximately 0.03 TC per day except for August. The DGR for Cat. 1 cases was greater than inactive cases. The Cat. 4 cases were slightly exceptional in that the DGRs during May and August led those in all other cases but decreased remarkably after September. These results provide quantitative evidence to support the common understanding that a stronger monsoon trough has a greater possibility of generating a TC.

\section{CONCLUSIONS AND DISCUSSION}

\subsection{Conclusions}

The present study performed a statistical examination on the relationship between the northwestern Pacific monsoon trough and tropical cyclogenesis using a daily monsoon trough index, which was proposed recently (Feng et al. 2020a). This index better captures the seasonal evolution of $\mathrm{TC}$ formations than a simple index using relative vorticity, which has commonly been used in previous studies. Based on this index, the large-scale daily circulation over the western North Pacific from 1979 to 2020 was categorized as
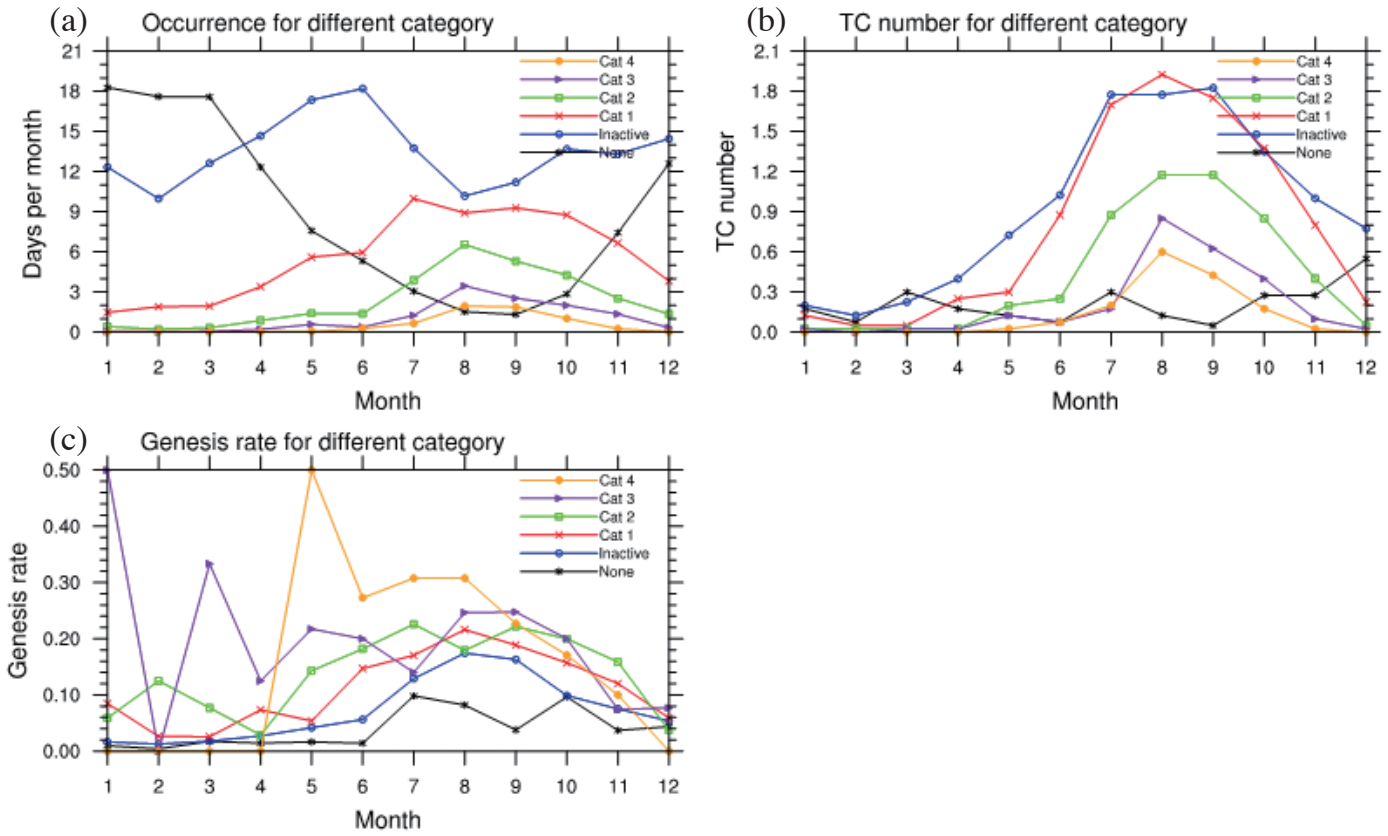

Fig. 8. Seasonal evolution of (a) occurrence day, (b) TC number, and (c) daily genesis rate for different monsoon trough categories. 
NoMT, inactive, and active (Cat. 1 - 4) based on the value of the MTI. The connection between the value of the MTI and the morphology of the monsoon trough was established for further examination. A total of 734 (57.3\%) TCs formed associated with an active monsoon trough. The intensity of the monsoon trough affects the average TC genesis latitude and longitude. A stronger monsoon trough favors eastward generation, exhibiting different track types due to different steering flows. The genesis capacity of the monsoon trough was examined using the DGR. The climatological DGR was 0.084 , and one TC formed every twelve days. The rate increased to one TC formation every four days when an extraordinarily strong monsoon trough existed over the western North Pacific (Cat. 4). The average genesis rate ranged from 0.139 to 0.246 with an active monsoon trough (Cat. 1 - 4). These results provide a statistical understanding of the occurrence of the active monsoon trough and related tropical cyclogenesis.

\subsection{Discussion}

Previous studies have established a connection between the monsoon trough and tropical cyclogenesis based on a multimonth mean (e.g., Wu et al. 2012). This method may overestimate the contribution of monsoon troughs to $\mathrm{TC}$ formation since the days without monsoon troughs are counted for time averaging (Molinari and Vollaro 2013). As indicated in Fig. 8a, approximately one-third of the days do not have an active monsoon trough, even in August, which is the most active month for the monsoon trough. The present study excluded days without an active monsoon trough for composition. Statistically, $57.3 \%$ of TCs form in association with the monsoon trough, which is lower than previous results by Ritchie and Holland (1999) and Molinari and Vollaro (2013). One plausible reason for this is that the present study does not count TCs formed in an inactive monsoon trough $(34.9 \%)$. The percentage of $57.3 \%$ is close to that of Yoshida and Ishikawa (2013), who suggested that 58\% of TCs are formed in the monsoon trough. Moreover, the current approach overestimated the percentage, as the TCs that formed outside the region of the monsoon trough were counted. A pattern identification method similar to that used by Yoshida and Ishikawa (2013) should be integrated to exclude formation events outside the monsoon trough region.

A stronger monsoon trough usually leads to a higher TC genesis frequency, which has been proposed based on a multimonth averaging in previous studies (e.g., Wu et al. 2012). Using a composite method of daily data, the present study provides a quantitative estimation to represent the genesis capacity of the monsoon trough from 0.139 to $0.246 \mathrm{TC}$ per day through the boreal summer. However, the genesis rate of the monsoon trough with a certain intensity also changes with the season in which the peak genesis rate occurs in August or September. Supposing that the mon- soon trough is the only factor that impacts TC genesis, the genesis rate for the monsoon trough with a certain intensity is expected to change little as the strength of the monsoon trough is restricted by the index. Such a result implies a nonnegligible role of other large-scale or synoptic-scale factors in modulating TC genesis, i.e., the upper-level tropospheric trough (Wang and Wu 2016; Feng et al. 2020b), equatorial waves (Dickinson and Molinari 2002; Feng et al. 2016, 2020c, d), cross-equatorial flow (Love 1985; Feng et al. 2017), and local sea surface temperature (Fu et al. 2012; Tang et al. 2020). With these factors, the genesis rate for Cat. 2 monsoon troughs changes from 0.03 (April) to 0.23 (July) TC per day (Fig. 8), exerting a remarkable impact. As the critical role of the monsoon trough is to provide cyclonic relative vorticity, the impacts of different factors may be decomposed by the genesis potential index (Emanuel and Nolan 2004) to address the relative role of these coupled systems. These results will be reported in the future.

Acknowledgements The authors appreciate two anonymous reviewers for their insightful comments. This study was supported by the National Natural Science Foundation of China (Grant No. 42076016, 41775056), the Fundamental Research Funds for the Central Universities (Grant No. B210203026 and B210202132), and National Natural Science Foundation of China (42175063).

\section{REFERENCES}

Briegel, L. M. and W. M. Frank, 1997: Large-scale influences on tropical cyclogenesis in the western North Pacific. Mon. Weather Rev., 125, 1397-1413, doi: 10.1175/1520-0493(1997)125<1397:LSIOTC>2.0. $\mathrm{CO} ; 2$. [Link]

Cao, X., G. Chen, and W. Chen, 2013: Tropical cyclogenesis induced by ITCZ breakdown in association with synoptic wave train over the western North Pacific. Atmos. Sci. Lett., 14, 294-300, doi: 10.1002/asl2.452. [Link]

Cao, X., T. Li, M. Peng, W. Chen, and G. Chen, 2014a: Effects of monsoon trough intraseasonal oscillation on tropical cyclogenesis over the western North $\mathrm{Pa}$ cific. J. Atmos. Sci., 71, 4639-4660, doi: 10.1175/JASD-13-0407.1. [Link]

Cao, X., T. Li, M. Peng, W. Chen, and G. Chen, 2014b: Effects of monsoon trough interannual variation on tropical cyclogenesis over the western North Pacific. Geophys. Res. Lett., 41, 4332-4339, doi: 10.1002/2014GL060307. [Link]

Dickinson, M. and J. Molinari, 2002: Mixed Rossby-gravity waves and western Pacific tropical cyclogenesis. Part I: Synoptic evolution. J. Atmos. Sci., 59, 21832196, doi: 10.1175/1520-0469(2002)059<2183:MRG$\mathrm{WAW}>2.0 . \mathrm{CO} ; 2$. [Link] 
Emanuel, K. A. and D. S. Nolan, 2004: Tropical cyclone activity and the global climate system. Preprints, 26th Conference on Hurricanes and Tropical Meteorology, Miami, FL, Amer. Meteor. Soc., 10A.2. Available at https://ams.confex.com/ams/pdfpapers/75463.pdf.

Feng, T., G.-H. Chen, R.-H. Huang, and X.-Y. Shen, 2014: Large-scale circulation patterns favourable to tropical cyclogenesis over the western North Pacific and associated barotropic energy conversions. Int. J. Climatol., 34, 216-227, doi: 10.1002/joc.3680. [Link]

Feng, T., X.-Q. Yang, W. Zhou, R. Huang, L. Wu, and D. Yang, 2016: Synoptic-scale waves in sheared background flow over the western North Pacific. J. Atmos. Sci., 73, 4583-4603, doi: 10.1175/JAS-D-16-0064.1. [Link]

Feng, T., X. Shen, R. Huang, and G. Chen, 2017: Influence of the interannual variation of cross-equatorial flow on tropical cyclogenesis over the western North Pacific. J. Trop. Meteorol., 23, 68-80, doi: 10.16555/j.10068775.2017.01.007. [Link]

Feng, T., X.-Q. Yang, X. Sun, D. Yang, and C. Chu, 2020a: Reexamination of the climatology and variability of the northwest Pacific monsoon trough using a daily index. J. Clim., 33, 5919-5938, doi: 10.1175/JCLID-19-0459.1. [Link]

Feng, T., X.-Q. Yang, L. Wu, R. Huang, and D. Yang, 2020b: How do the monsoon trough and the tropical upper-tropospheric trough affect synoptic-scale waves: A comparative study. J. Meteorol. Soc. Jpn., 98, 735754, doi: 10.2151/jmsj.2020-037. [Link]

Feng, T., X.-Q. Yang, J.-Y. Yu, and R. Huang, 2020c: Convective coupling in tropical-depression-type waves. Part I: Rainfall characteristics and moisture structure. J. Atmos. Sci., 77, 3407-3422, doi: 10.1175/JASD-19-0172.1. [Link]

Feng, T., J.-Y. Yu, X.-Q. Yang, and R. Huang, 2020d: Convective coupling in tropical-depression-type waves. Part II: Moisture and moist static energy budgets. J. Atmos. Sci., 77, 3423-3440, doi: 10.1175/JASD-19-0173.1. [Link]

Ferreira, R. N. and W. H. Schubert, 1997: Barotropic Aspects of ITCZ Breakdown. J. Atmos. Sci., 54, 261-285, doi: 10.1175/1520-0469(1997)054<0261:BAOIB>2.0. CO;2. [Link]

Fu, B., M. S. Peng, T. Li, and D. E. Stevens, 2012: Developing versus Nondeveloping Disturbances for Tropical Cyclone Formation. Part II: Western North Pacific. Mon. Weather Rev., 140, 1067-1080, doi: 10.1175/2011MWR3618.1. [Link]

Gao, J. and T. Li, 2011: Factors controlling multiple tropical cyclone events in the western North Pacific. Mon. Weather Rev., 139, 885-894, doi: 10.1175/2010MWR3340.1. [Link]

Gray, W. M., 1968: Global view of the origin of tropical disturbances and storms. Mon. Weather Rev., 96, 669700, doi: 10.1175/1520-0493(1968)096<0669:GVOT OO $>2.0 . \mathrm{CO} ; 2$. [Link]

Ha, Y., Z. Zhong, Y. Hu, and X. Yang, 2013: Influences of ENSO on western North Pacific tropical cyclone kinetic energy and its meridional transport. J. Clim., 26, 322-332, doi: 10.1175/JCLI-D-11-00543.1. [Link]

Harr, P. A. and C.-C. Wu, 2011: Tropical cyclone characteristics and monsoon circulations. In: Chang, C.-P., Y. Ding, N.-C. Lau, R. H. Johnson, B. Wang, and T. Yasunari (Eds.), The Global Monsoon System: Research and Forecast, 2 Edition, World Scientific Series on Asia-Pacific Weather and Climate, Volume 5, World Scientific, 357-372, doi: 10.1142/9789814343411_0021. [Link]

Holland, G. J., 1995: Scale interaction in the western Pacific monsoon. Meteorol. Atmos. Phys., 56, 57-79, doi: 10.1007/BF01022521. [Link]

Hsu, H.-H., C.-H. Hung, A.-K. Lo, C.-C. Wu, and C.W. Hung, 2008: Influence of tropical cyclones on the estimation of climate variability in the tropical western North Pacific. J. Clim., 21, 2960-2975, doi: 10.1175/2007JCLI1847.1. [Link]

Huangfu, J., R. Huang, W. Chen, T. Feng, and L. Wu, 2017: Interdecadal variation of tropical cyclone genesis and its relationship to the monsoon trough over the western North Pacific. Int. J. Climatol., 37, 3587-3596, doi: 10.1002/joc.4939. [Link]

Huangfu, J., R. Huang, W. Chen, and T. Feng, 2018: Causes of the active typhoon season in 2016 following a strong El Niño with a comparison to 1998. Int. J. Climatol., 38, e1107-e1118, doi: 10.1002/joc.5437. [Link]

Kanamitsu, M., W. Ebisuzaki, J. Woollen, S.-K. Yang, J. J. Hnilo, M. Fiorino, and G. L. Potter, 2002: NCEPDOE AMIP-II Reanalysis (R-2). Bull. Amer. Meteorol. Soc., 83, 1631-1644, doi: 10.1175/BAMS-83-11-1631. [Link]

Knapp, K. R., M. C. Kruk, D. H. Levinson, H. J. Diamond, and C. J. Neumann, 2010: The International Best Track Archive for Climate Stewardship (IBTrACS). Bull. Amer. Meteorol. Soc., 91, 363-376, doi: 10.1175/2009BAMS2755.1. [Link]

Knapp, K. R., H. J. Diamond, J. P. Kossin, M. C. Kruk, and C. J. Schreck III, 2018: International Best Track Archive for Climate Stewardship (IBTrACS) Project, Version 4. NOAA National Centers for Environmental Information, doi: 10.25921/82ty-9e16. [Link]

Kurihara, Y., M. A. Bender, and R. J. Ross, 1993: An initialization scheme of hurricane models by vortex specification. Mon. Weather Rev., 121, 2030-2045, doi: 10.1175/1520-0493(1993)121<2030:AISOHM>2.0. CO;2. [Link]

Kurihara, Y., M. A. Bender, R. E. Tuleya, and R. J. Ross, 1995: Improvements in the GFDL hurricane prediction system. Mon. Weather Rev., 123, 2791-2801, doi: 
10.1175/1520-0493(1995)123<2791:IITGHP>2.0. CO;2. [Link]

Lander, M. A., 1994: Description of a monsoon gyre and Its effects on the tropical cyclones in the western North Pacific during August 1991. Weather Forecast., 9, 640654, doi: 10.1175/1520-0434(1994)009<0640:DOAMGA>2.0.CO;2. [Link]

Lander, M. A., 1996: Specific tropical cyclone track types and unusual tropical cyclone motions associated with a reverse-oriented monsoon trough in the western North Pacific. Weather Forecast., 11, 170-186, doi: 10.1175/1520-0434(1996)011<0170:STCTTA>2.0. CO;2. [Link]

Li, C., R. Lu, and G. Chen, 2017: Promising prediction of the monsoon trough and its implication for tropical cyclone activity over the western North Pacific. Environ. Res. Lett., 12, 074027, doi: 10.1088/1748-9326/ aa71bd. [Link]

Liang, J. and L. Wu, 2015: Sudden Track Changes of Tropical Cyclones in Monsoon Gyres: Full-Physics, Idealized Numerical Experiments. J. Atmos. Sci., 72, 13071322, doi: 10.1175/JAS-D-13-0393.1. [Link]

Love, G., 1985: Cross-equatorial interactions during tropical cyclogenesis. Mon. Weather Rev., 113, 1499-1509, doi: 10.1175/1520-0493(1985)113<1499:CEIDTC $>2$. $0 . \mathrm{CO} ; 2$. [Link]

Molinari, J. and D. Vollaro, 2013: What percentage of western North Pacific tropical cyclones form within the monsoon trough? Mon. Weather Rev., 141, 499-505, doi: 10.1175/MWR-D-12-00165.1. [Link]

NCEP/NWS/NOAA/DOC (National Centers for Environmental Prediction/National Weather Service/NOAA/ U.S. Department of Commerce), 2000: NCEP/DOE Reanalysis 2 (R2). Research Data Archive at the National Center for Atmospheric Research, Computational and Information Systems Laboratory, doi: 10.5065/ KVQZ-YJ93. (Accessed 9 May 2020) [Link]

Ritchie, E. A. and G. J. Holland, 1999: Large-scale patterns associated with tropical cyclogenesis in the western Pacific. Mon. Weather Rev., 127, 2027-2043, doi: 10.1175/1520-0493(1999)127<2027:LSPAWT>2.0. $\mathrm{CO} ; 2$. [Link]

Takayabu, Y. N. and T. Nitta, 1993: 3-5 day-period disturbances coupled with convection over the tropical Pacific Ocean. J. Meteorol. Soc. Jpn., 71, 221-246, doi: 10.2151/jmsj1965.71.2_221. [Link]

Tan, P.-H., J.-Y. Tu, L. Wu, H.-S. Chen, and J.-M. Chen, 2019: Asymmetric relationships between El NiñoSouthern Oscillation and entrance tropical cyclones in the South China Sea during fall. Int. J. Climatol., 39, 1872-1888, doi: 10.1002/joc.5921. [Link]
Tang, Y., J. Huangfu, R. Huang, and W. Chen, 2020: Surface warming reacceleration in offshore China and its interdecadal effects on the East Asia-Pacific climate. Sci. Rep., 10, 14811, doi: 10.1038/s41598-020-718626. [Link]

Wang, B. and LinHo, 2002: Rainy season of the AsianPacific summer monsoon. J. Clim., 15, 386-398, doi: 10.1175/1520-0442(2002)015<0386:RSOTAP >2.0. CO;2. [Link]

Wang, C. and L. Wu, 2016: Interannual Shift of the Tropical Upper-Tropospheric Trough and Its Influence on Tropical Cyclone Formation over the Western North Pacific. J. Clim., 29, 4203-4211, doi: 10.1175/JCLID-15-0653.1. [Link]

Wu, L., Z. Wen, R. Huang, and R. Wu, 2012: Possible linkage between the monsoon trough variability and the tropical cyclone activity over the western North Pacific. Mon. Weather Rev., 140, 140-150, doi: 10.1175/ MWR-D-11-00078.1. [Link]

Wu, L., H. Zhang, T. Feng, and Y. Tang, 2020a: Tropical cyclones and multiscale climate variability: The active western North Pacific Typhoon season of 2018. Sci. China Earth Sci., 63, 1-11, doi: 10.1007/s11430-0199474-4. [Link]

Wu, L., H. Zhang, J.-M. Chen, and T. Feng, 2020b: Characteristics of tropical cyclone activity over the South China Sea: Local and nonlocal tropical cyclones. Terr. Atmos. Ocean. Sci., 31, 261-271, doi: 10.3319/ TAO.2019.07.01.02. [Link]

$\mathrm{Wu}, \mathrm{R} ., 2002$ : Processes for the northeastward advance of the summer monsoon over the western North Pacific. J. Meteorol. Soc. Jpn., 80, 67-83, doi: 10.2151/ jmsj.80.67. [Link]

Yoshida, R. and H. Ishikawa, 2013: Environmental factors contributing to tropical cyclone genesis over the western North Pacific. Mon. Weather Rev., 141, 451-467, doi: 10.1175/MWR-D-11-00309.1. [Link]

Zhao, H., R. Yoshida, and G. B. Raga, 2015: Impact of the Madden-Julian Oscillation on Western North Pacific Tropical Cyclogenesis Associated with Large-Scale Patterns. J. Appl. Meteorol. Climatol., 54, 1413-1429, doi: 10.1175/JAMC-D-14-0254.1. [Link]

Zhou, X., R. Lu, and G. Chen, 2018: Impact of interannual variation of synoptic disturbances on the tracks and landfalls of tropical cyclones over the western North Pacific. Adv. Atmos. Sci., 35, 1469-1477, doi: 10.1007/ s00376-018-8055-0. [Link]

Zong, H. and L. Wu, 2015: Synoptic-scale influences on tropical cyclone formation within the western North Pacific monsoon trough. Mon. Weather Rev., 143, 3421-3433, doi: 10.1175/MWR-D-14-00321.1. [Link] 